\title{
Refractory epilepsy and obstructive sleep apnea: is there an association?
}

\author{
Hebatallah R. Rashed', Mohamad A. Tork', Lobna M. El-Nabil', Naglaa M. El-Khayat', Nahed S. Ahmed', \\ Salem T. Abdelhady ${ }^{1}$, Khaled O. Abdulghani ${ }^{2^{*}}$ (D) and M. Ossama Abdulghani ${ }^{1}$
}

\begin{abstract}
Background: A high prevalence of obstructive sleep apnea (OSA) has been reported in medically refractory epilepsy patients, and there is increasing evidence that treatment of OSA in refractory epilepsy patients would reduce seizure frequency.

Objective: Studying the frequency of occurrence of OSA in a group of refractory epilepsy patients, compared to a matched group with medically controlled epilepsy.

Methods: Sixty patients with epilepsy, 30 patients with controlled epilepsy (group I), and 30 patients with refractory epilepsy (group II) were included. All patients underwent overnight polysomnogram and sleep EEG and completed Sleep Apnea Sleep Disorders Questionnaire (SASDQ). All patients had normal general and neurological examination.

Results: The frequency of OSA was found to be $10 \%$ in patients with controlled epilepsy, while its frequency in patients with refractory epilepsy was found to be $16.7 \%$, yet this was statistically insignificant. In addition, $\mathrm{O}_{2}$ desaturation nadir was higher in group II, compared to group I with no statistical significance. In the controlled epilepsy group, we found that older patients tend to have higher Apnea-Hypopnea Index (AHI). Moreover, it was found that older subjects, with early onset of epilepsy, and longer duration of the illness tend to have higher AHI in group II.
\end{abstract}

Conclusion: There is an association between refractory epilepsy and OSA, especially regarding $\mathrm{O}_{2}$ desaturation during sleep. In addition, older age, early onset of epilepsy, and longer duration of illness are independent risk factors for the OSA in patients with refractory epilepsy.

Keywords: Obstructive sleep apnea, Refractory epilepsy, Polysomnogram, Apnea hypopnea index

\section{Introduction}

It is noted that obstructive sleep apnea (OSA) coexists with epilepsy (in $10 \%$ of adult epilepsy patients, $20 \%$ of children with epilepsy, and up to $30 \%$ of drug-resistant epilepsy patients) [1]. The potential mechanisms underlying the probable association between OSA and increased seizure frequency could be related to changes in sleep architecture, intermittent hypoxia, or sleep deprivation [2]. Therefore, it is not surprising that treatment of OSA may decrease seizure frequency [3].

In the present study, we aim at studying the frequency of occurrence of OSA in a group of refractory epilepsy

\footnotetext{
* Correspondence: Khaled.abdulghani@med.helwan.edu.eg

${ }^{2}$ Neurology and Psychiatry Department, Helwan University School of

Medicine, Cairo, Egypt

Full list of author information is available at the end of the article
}

patients, compared to a matched group with medically controlled epilepsy.

\section{Material and methods}

This cross-sectional, retrospective study was carried out on 60 adult epileptic patients treated at Ain Shams University Hospitals. Subjects provided informed consent prior to the participating in any study-related activities. This study was approved by the ethical committee of the Faculty of Medicine, Ain Shams University. Patients' age ranged from 18 to 57 years old. They were diagnosed on clinical and electroencephalography (EEG) basis according to the 1989 classification and terminology of the International League Against Epilepsy (ILAE) [4]. All subjects had normal neurological and general examination. Subjects were divided into two groups: group (I) 
included 30 patients with controlled epilepsy, controlled on medical treatment, and have $\leq 1$ seizure/month, and group (II) included 30 patients with refractory epilepsy, defined as persistence of seizures, more than one seizure a month, after trials of at least two antiepileptic drugs (AEDs) with maximally tolerated doses sequentially or in combination, and duration of AED treatment of at least 2 years [5].

We excluded patients having seizures secondary to drugs, infection, neoplasia, demyelination, degenerative diseases, or metabolic disease. We also excluded patients with medical illnesses affecting their sleep pattern (as chronic liver disease, hypothyroidism), patients with history of OSA prior to the diagnosis of epilepsy or drug intake that could affect sleep such as hypnotics or sedatives, and patients who recently discontinued their AEDs. In addition, we excluded patients with narcolepsy and any other primary sleep disorder requiring intervention with medication and potentially affecting the results of the study. Subjects were able to withdraw from the study at any time. Reasons for early withdrawal included development of a clinically relevant change in medical condition, consent withdrawal, and lack of transportation, as participation required an overnight stay in the sleep laboratory.

Subjects underwent an overnight polysomnography (PSG) with electroencephalography (EEG) recording for at least $6 \mathrm{~h}$ using a Nihon Kohden Neurofax-1200 EEG/ PSG system (Tokyo, Japan). We used 18 channels for EEG, 2 channels for electro-oculography, 1 channel for each chin electromyography, and 4 channels for legs electromyography. We also used a naso-oral thermistor and nasal pressure transducer to monitor airflow and piezo-electric belts for thoracic and abdominal efforts, in addition to ECG, pulse oximetry, snoring, body position, and video recordings. We followed the American Association of Sleep Medicine Scoring Manual to perform sleep staging and event scoring [6]. We tallied apneas and hypopneas to derive the Apnea-Hypopnea Index (AHI), which is the number of respiratory events per sleep hour. Patients having an AHI $>5$ were identified as having OSA. OSA severity is defined as mild for AHI $>5$ and $<15$, moderate for $>15$ and $<30$, and severe for AHI $>30$ [7].

All subjects answered Sleep Apnea Sleep Disorders Questionnaire (SASDQ) [8], a 12-item validated measure of sleep-related breathing disorders, for the screening of apnea before proceeding to polysomnography, based on variables including loud snoring, age, body mass index, tobacco use, and hypertension. Total score ranges from 0 to 60 . In the original validation, cutoffs of 32 or higher for women and 36 or higher for men correlated well with having a diagnosis of OSA by PSG. Cutoffs of 26 or higher for women and 29 or higher for men were found to correlate better with PSG in epilepsy patients [9].
Subjects underwent a structured interview ascertaining sleep and wake patterns, nighttime behaviors, and sleep disorder symptoms [10]. Medical history and epilepsy history, including epilepsy type, management, and seizure frequency, were also taken.

\section{Statistical analysis}

Data were collected, coded, and entered to a personal computer IBM compatible. The data were analyzed with the SPSS version 11.0.1 (Statistical Package for the Social Sciences, Chicago, USA). Descriptive statistics were displayed as mean \pm standard deviation (SD) for continuous data. Student's $t$ test used for comparison of parametric data between the independent groups, Pearson's correlation coefficient $(r)$ test to indicate correlation between different variables, and the chi-square test for comparison of qualitative data. The level of statistical significance ( $p$ value) was set at 0.05 .

\section{Results}

The demographic data for both groups are shown in Table 1. There were no significant age, gender, or BMI differences between controlled and refractory epilepsy patients.

The $\mathrm{O}_{2}$ desaturation nadir and frequency of OSA were more in patient with refractory epilepsy versus those with controlled epilepsy; however, this difference was found to be statistically insignificant (Table 2).

We found that three out of five refractory epilepsy patients with OSA $(60 \%)$ and two out of three patients in the controlled epilepsy group with OSA (66.7\%) had mild OSA. Regarding moderate OSA, we got two out of five refractory epilepsy patients $(40 \%)$ and one patient (33.3\%) of the medically controlled epilepsy group. Thus, refractory epilepsy patients tended to get higher degrees of apnea, compared to the medically controlled epilepsy patients, which tended to show milder forms. However, this was not significant statistically.

AHI was found to be higher in patients with refractory epilepsy and OSA, who showed also more decrease in the $\mathrm{O}_{2}$ level during sleep, compared to the controlled epilepsy group with OSA (Table 3).

Compared with medically controlled patient with OSA, patients with refractory epilepsy and OSA had their first seizure at a younger age, with a longer

Table 1 Comparison between both groups regarding demographic data

\begin{tabular}{llll}
\hline Variable & Group I & Group II & $p$ value \\
\hline Age of patients in years (mean \pm SD) & $29.1 \pm 10.8$ & $25.1 \pm 7.3$ & 0.0947 \\
Male \% $(n)$ & $40 \%(12)$ & $46.7 \%(14)$ & 0.6030 \\
Female \% $(n)$ & $60 \%(18)$ & $53.3 \%(16)$ & 0.6030 \\
BMI (mean \pm SD) & $25.86 \pm 4.9$ & $26.2 \pm 5$ & 0.7677 \\
\hline
\end{tabular}

$n$ number, $S D$ standard deviation, $B M I$ body mass index 
Table 2 Comparison between both groups regarding patients having OSA

\begin{tabular}{llll}
\hline Variable & Group I & Group II & $p$ value \\
\hline $\mathrm{O}_{2}$ desaturation nadir (mean \pm SD) & $90.9 \pm 6.5$ & $87.5 \pm 9.4$ & 0.0539 \\
OSA \% $(n)$ & $10 \%(3)$ & $16.7 \%(5)$ & 0.4472 \\
\hline
\end{tabular}

$n$ number, $S D$ standard deviation, OSA obstructive sleep apnea, $\mathrm{O}_{2}$ oxygen

duration of epilepsy. We found that patients with OSA in the refractory epilepsy group were taking a higher number of AEDs than those in the controlled epilepsy group, which was statistically significant (Table 4).

Patients with medically refractory epilepsy and OSA reported more frequent sleep complaints, specifically excessive daytime somnolence (EDS), and this was statistically significant (Table 5). Snoring also was reported more frequently in those with refractory epilepsy than patients with medically controlled epilepsy, yet this was not statistically significant.

Compared to well-controlled epileptic patients with no OSA, those with OSA were found to be older (47.3 \pm 15.9 versus $27.1 \pm 8.2$ in patients without OSA) and with higher BMI. Yet, there was no statistical significance in gender distribution. In addition, we found delayed age of onset of epilepsy in patients with OSA as compared to those without OSA (41.66 \pm 14.7 versus $22.1 \pm 8.3$; respectively), and this was statistically significant. Regarding sleep symptoms, patients with OSA in group I reported more frequent sleep symptoms than those without OSA. Snoring was the most common symptom reported among those patients $(66.7 \%)$ and again this was statistically significant (Table 6).

We did not find any statistical significance regarding gender distribution and BMI among those with or without OSA in the refractory epilepsy group. Patients with OSA had significantly delayed age of onset of epilepsy compared with patients without OSA $(20.2 \pm 3.4$ versus $15.48 \pm 6.2$; respectively). Moreover, patients in the refractory group with OSA showed significantly longer duration of epilepsy compared to those without OSA (14.8 \pm 6.2 versus $7.56 \pm 5.3$; respectively). As expected, patients having OSA have greater SASDQ score, which was statistically significant. All patients suffering from OSA in the refractory epilepsy group reported sleep symptoms in the form of EDS and snoring, which was also statistically significant (Table 7).

Reviewing the correlations between $\mathrm{AHI}$ and variables of interest in patients with medically controlled epilepsy, it was found that age is a significant independent risk factor of having OSA in the controlled epilepsy group ( $p$ value $=0.023$ ). On the other hand, reviewing the correlations between AHI and variables of interest, as age of onset, duration of epilepsy, and BMI, in subjects with refractory epilepsy, it was found that these variables are significantly independent factors in determining patients with OSA (Table 8).

\section{Discussion}

Epilepsy and OSA are two common disorders that can coexist and profoundly exacerbate each other [11]. Studies showed that patients with epilepsy are at higher risk for apnea than the general population, due to sedentary lifestyle or the effects of AEDs on OSA [1]. Moreover, OSA is underdiagnosed particularly in epileptic patients [12]. Prevalence of sleep apnea in epileptics varies in literature, ranging from $20 \%$ up to nearly $60 \%$ [13].

Sleep fragmentation in OSA which causes increased sleep stage transitions, sleep deprivation, cerebral hypoxemia, decreased cardiac output, and cardiac arrhythmias can facilitate interictal epileptiform spikes and precipitate epileptic seizures, whereas the latter can induce apneas [14-16].

There have been several studies showing improvement of epileptic seizures with treatment of OSA, where more than half of these patients showed improvement in seizure frequencies independent from AED changes [1719]. Positive airway pressure, positional therapy, or upper airway surgery reduces obesity and blood pressure and improves cognition, mood, and daytime sleepiness, which in turn reduced seizures in $40-86 \%$ of people with epilepsy and OSA [20, 21]. There is report of direct effect of CPAP on reducing the interictal spikes and therefore potentially reducing epileptogenicity [22].

Our findings support previous studies that show a higher percentage of OSA in epilepsy patients compared to the general population [23-25]. Increased sleep apnea in the refractory group is agreeing with previous studies. In a study by Malow and colleagues, the prevalence of OSA was $30 \%$ in intractable epilepsy group and $10 \%$ of unselected adult epilepsy group [1]. Another study by Zanzmera and colleagues showed that the prevalence of OSA was $20 \%$ in refractory epilepsy versus none in medically controlled group [26]. However, we did not find a statistically significant higher OSA rate in refractory

Table 3 Comparison between respiratory events among patients with OSA in both groups

\begin{tabular}{llll}
\hline Variable & $\begin{array}{l}\text { Group I with OSA } \\
n=3\end{array}$ & $\begin{array}{l}\text { Group II with OSA } \\
n=5\end{array}$ & $p$ value \\
\hline AHI (mean \pm SD) & $8.7 \pm 0.6$ & $12.9 \pm 5.2$ & 0.2221 \\
$\mathrm{O}_{2}$ desaturation nadir (mean \pm SD) & $78.3 \pm 11$ & $74.6 \pm 16$ & 0.3901 \\
\hline
\end{tabular}

$n$ number, $S D$ standard deviation, OSA obstructive sleep apnea, $A H I$ Apnea-Hypopnea Index, $\mathrm{O}_{2}$ oxygen 
Table 4 Comparison between epilepsy related clinical data among patients with OSA in both groups

\begin{tabular}{llll}
\hline Variable & $\begin{array}{l}\text { Group I with OSA } \\
n=3\end{array}$ & $\begin{array}{l}\text { Group II with OSA } \\
n=5\end{array}$ & $p$ value \\
\hline Age at onset of epilepsy in years (mean \pm SD) & $41.67 \pm 14.7$ & $20.2 \pm 3.4$ & $0.01679^{*}$ \\
Duration of epilepsy in years (mean \pm SD) & $5.7 \pm 2.5$ & $14.8 \pm 2.4$ & $0.04168^{*}$ \\
Number of AEDs & $1 \pm 0$ & $2.8 \pm 0.7$ & $0.00858^{*}$ \\
\hline
\end{tabular}

$n$ number, $S D$ standard deviation, OSA obstructive sleep apnea, AEDs anti-epileptic drugs. *Significant

versus controlled epilepsy patients, which is in accordance with a study by $\mathrm{Li}$ and colleagues [25].

The reason for low prevalence in our study can be attributed to difference in patients' selection as other studies included only the patients who complained of sleep disorders where higher prevalence of OSA is suspected, whereas in our study, we aimed to investigate OSA in epileptic patients regardless the presence of sleep complaints. However, more reasons need to be explored in the future [21].

Our study is the first Egyptian study, to our knowledge, to compare sleep-related clinical data associated with OSA, between controlled and refractory epilepsy groups. In refractory epilepsy patients with OSA, we found significantly frequent sleep disturbance symptoms and younger age of seizure onset compared with patients with medically controlled epilepsy and OSA, which is in accordance with other studies [25, 26].

About $40 \%$ of our refractory epilepsy patients with OSA showed $\mathrm{O}_{2}$ desaturation to critical levels (below 70\%), which may question the causes of Sudden Unexplained Death in Epileptic Patients (SUDEP) especially in refractory epilepsy patients. SUDEP represents the main cause of death in patients with refractory epilepsy [27]. Cardiac arrhythmias, respiratory dysfunctions, and dysregulation of systemic or cerebral circulation have been suggested as potential pathophysiological mechanisms. Moreover, clinical data suggest that SUDEP occur preferentially during sleep [28]. In our study, we hypothesize that these apneic events, with this severe desaturation may help to unravel the epileptogenesis of SUDEP, and this is in accordance to a previous study by Dominici and colleagues [29]. Thus, better understanding the role of apnea and epilepsy in the spectrum of SUDEP may help to clarify the epileptogenesis of this syndrome.

Table 5 Comparison between sleep related clinical data among patients with OSA in both groups

\begin{tabular}{llll}
\hline OSA & \multicolumn{3}{l}{} \\
\hline Variable & $\begin{array}{l}\text { Group I with OSA } \\
n=3\end{array}$ & $\begin{array}{l}\text { Group II with OSA } \\
n=5\end{array}$ & $p$ value \\
\hline SASDQ (mean \pm SD) & $33 \pm 12$ & $32 \pm 10.7$ & 0.90665 \\
Snoring \% $(n)$ & $2(66.7 \%)$ & $5(100 \%)$ & 0.16758 \\
EDS \% $(n)$ & $0(0 \%)$ & $5(100 \%)$ & $0.00466^{*}$ \\
\hline$n$ number, SD standard deviation, OSA obstructive sleep apnea, SASDQ Sleep
\end{tabular}

Few previous studies have assessed the risk factors for OSA in an epilepsy population. They showed that patients with epilepsy and OSA tend to be older, with higher BMI, more frequently males, and sleepier than epileptic patients without OSA [30]. Foldvary-Schaefer and colleagues in 2012 found that traditional OSA risk factors of older age, higher BMI, and male gender were predictive of OSA in epilepsy patients [24]. Abad-Alegria and colleagues in 1997 found that those with OSA were more likely to be males, with higher BMI and a history of snoring, witnessed apnea, and nocturnal seizures [13]. $\mathrm{Li}$ and colleagues reported higher BMI, snoring, sleep disturbance symptoms, and younger age of seizure onset in refractory epilepsy patients with OSA versus patients with controlled epilepsy with OSA [25].

In addition to these factors, we found also that subjects with OSA and medically controlled epilepsy have experienced the first seizure at a later age, which was shown before in different studies [25, 30, 31]. Those with refractory epilepsy and co-existing OSA were older, with older age of onset of epilepsy, and longer duration of epilepsy as compared to those without OSA. However, they were not with higher BMI compared to the non-apneic patients, indicating that the occurrence of apnea in medically refractory epilepsy patients is independent on the weight of the patients, and thus, other factors should be considered: as the age of the patient, the duration of the illness, and the age of onset of the epilepsy, which may play role in the pathogenesis of the disease.

In our study, we found that age is an independent risk factor of having OSA in the controlled epilepsy group. Thus, older patients tend to have higher AHI. On the other hand, it was found that age of patients, age of onset of epilepsy, and duration of epilepsy are all

Table 6 Comparison between patients with and without OSA in group 1 regarding sleep history

Medically controlled epilepsy (group I)

\begin{tabular}{llll}
\hline Variable & Without OSA & With OSA & $p$ value \\
\hline SASDQ (mean \pm SD) & $20 \pm 6.6$ & $33 \pm 12$ & $0.00627^{*}$ \\
Sleep symptoms \% $(n)$ & $48.1 \%(13)$ & $66.7 \%(2)$ & 0.54186 \\
EDS \% $(n)$ & $11.1 \%(3)$ & $0 \%(0)$ & 0.54186 \\
Snoring \% $(n)$ & $7.4 \%(2)$ & $66.7 \%(2)$ & $0.00424^{*}$ \\
\hline
\end{tabular}

$n$ number, $S D$ standard deviation, OSA obstructive sleep apnea, SASDQ Sleep Apnea Sleep Disorder Questionnaire, EDS excessive daytime somnolence. *Significant 
Table 7 Comparison between patients with and without OSA in group II regarding sleep-related clinical data

\begin{tabular}{llll}
\hline Refractory epilepsy (group II) & Without OSA & With OSA & $p$ value \\
\hline Variable & $18.6 \pm 5.7$ & $32 \pm 10.7$ & $0.00029^{*}$ \\
\hline SASDQ (mean \pm SD) & $32 \%(8)$ & $100 \%(5)$ & $0.00512^{*}$ \\
Sleep symptoms \% $(n)$ & $4 \%(1)$ & $100 \%(5)$ & $0.0001^{*}$ \\
EDS \% $(n)$ & $20 \%(5)$ & $100 \%(5)$ & $0.00054^{*}$ \\
Snoring \% $(n)$ &
\end{tabular}

$n$ number, SD standard deviation, OSA obstructive sleep apnea, SASDQ Sleep Apnea Sleep Disorders Questionnaire, EDS excessive daytime somnolence. *Significant

independent factors in determining patients with OSA in the refractory epilepsy group. We found that younger subjects, with early onset of epilepsy, and longer duration of the illness tend to have higher AHI. Thus, other factors should be considered in patients with refractory epilepsy and not only the traditional risk factors of the OSA, which may play role in the pathogenesis of the disease.

Excessive daytime somnolence and snoring are the most common complaints of OSA patients; however, we found that self-reported EDS were not helpful in predicting OSA in medically controlled patients, and this is in accordance with the study of Foldvary-Schaefer and colleagues in 2012 [24], possibly related to a ceiling effect of general sleepiness among epilepsy patients from diverse causes.

We studied patients referred to the adult epilepsy clinic regardless of their sleep problems. The included patients were not biased toward any sleep-related complaints.

Finally, our findings should be viewed more as hypothesis-generating and will require larger studies. Nevertheless, we hope that our results will prompt an increased routine screening of epileptic patients for sleep-related disorders.

\section{Conclusion}

There is an association between refractory epilepsy and OSA, especially regarding $\mathrm{O}_{2}$ desaturation during sleep. In addition, older age of the patient, early onset of epilepsy,

Table 8 Multivariate regression model assessing predictors of $\mathrm{AHI}$ in adults with refractory epilepsy

\begin{tabular}{lllll}
\hline & $\begin{array}{l}\text { Unstandardized } \\
\text { coefficients }\end{array}$ & $\begin{array}{l}p \\
\text { value }\end{array}$ & \multicolumn{2}{l}{$\begin{array}{l}\text { 95.0\% confidence } \\
\text { interval for B }\end{array}$} \\
\cline { 3 - 5 } & $B$ & & $\begin{array}{l}\text { Lower } \\
\text { bound }\end{array}$ & $\begin{array}{l}\text { Upper } \\
\text { bound }\end{array}$ \\
\hline (Constant) & -6.939 & 0.088 & -15.001 & 1.123 \\
Age of onset & -6.968 & $0.001^{*}$ & -10.949 & -2.988 \\
$\begin{array}{l}\text { Duration of } \\
\text { epilepsy }\end{array}$ & -6.869 & $0.001^{*}$ & -10.817 & -2.920 \\
BMl & 0.036 & & & \\
Age & 7.257 & 0.809 & -0.263 & 0.334 \\
\hline A & & $0.001^{*}$ & 3.320 & 11.195 \\
\hline
\end{tabular}

AHI Apnea-Hypopnea Index, BMI body mass index. *Significant and longer duration of illness are independent risk factors for the OSA in patients with refractory epilepsy.

\section{Recommendations}

More studies exploring individual clinical and polysomnographic details of sleep including a larger number of subjects in different subsets of medically refractory epilepsy patients are needed to be conducted, in future, to see if these results can be generalized to all refractory epilepsy patients. We recommend performing PSG in all of these patients suspected to have apnea or unexplained daytime somnolence, and before attributing sleep disorders in epilepsy to the disease itself, clinicians should consider the possibility of underlying disorders.

\section{Abbreviations \\ AEDs: Antiepileptic drugs; AHI: Apnea-Hypopnea Index; BMI: Body mass index; EDS: Excessive daytime somnolence; EEG: Electroencephalography; \\ ILAE: International League Against Epilepsy; $\mathrm{O}_{2}$ : Oxygen; OSA: Obstructive sleep apnea; PSG: Polysomnography; SASDQ: Sleep Apnea Sleep Disorders \\ Questionnaire}

\section{Acknowledgements}

None.

\section{Funding}

None.

\section{Availability of data and materials}

The datasets generated and analyzed during the current study are not publicly available due to institutional limitations, yet they are available from the corresponding author on reasonable request.

\section{Authors' contributions}

$\mathrm{OA}$ and HR made substantial contributions to the conception and design of the study; HR performed the acquisition of the data; MT, LE, NE, NA, and SA participated in the analysis and interpretation of the data; MT and KA have been involved in drafting the manuscript or revising it critically for important intellectual content; OA has given final approval of the version to be published. All authors agreed to be accountable for all aspects of the work in ensuring that questions related to the accuracy or integrity of any part of the work are appropriately investigated and resolved. All authors read and approved the final manuscript.

\section{Ethics approval and consent to participate}

This study was approved by the ethical committee of the Faculty of Medicine, Ain Shams University, number ASU 1069/2012, on the 4th of March 2012. All Subjects provided informed consent prior to the participating in any study-related activities.

\section{Consent for publication}

Not applicable.

\section{Competing interests}

The authors declare that they have no competing interests.

\section{Publisher's Note}

Springer Nature remains neutral with regard to jurisdictional claims in published maps and institutional affiliations.

\section{Author details}

${ }^{1}$ Neurology and Psychiatry Department, Faculty of Medicine Ain Shams University, Cairo, Egypt. ${ }^{2}$ Neurology and Psychiatry Department, Helwan University School of Medicine, Cairo, Egypt. 
Received: 6 September 2018 Accepted: 22 April 2019

Published online: 08 May 2019

\section{References}

1. Malow BA, Levy K, Maturen K, Bowes R. Obstructive sleep apnea is common in medically refractory epilepsy patients. Neurology. 2000;55:1002-7.

2. Jain SV, Simakajornboon S, Shapiro SM, Morton LD, Leszczyszyn DJ, Simakajornboon N. Obstructive sleep apnea in children with epilepsy: prospective pilot trial. Acta Neurol Scand. 2012;125:e3-6.

3. Urbano F, Roux F, Schindler J, Mohsenin V. Impaired cerebral autoregulation in obstructive sleep apnea. J Appl Physiol. 2008;105:1852-7.

4. Manni R, Tartara A. Evaluation of sleepiness in epilepsy. Clin Neurophysiol. 2000:111(S2):111-4.

5. Kwan P, Brodie MJ. Early identification of refractory epilepsy. New Engl J Med. 2000;342:314-9.

6. Berry RB, Brooks R, Gamaldo CE, et al. The AASM Manual for the Scoring of Sleep and Associated Events: Rules, Terminology and Technical Specifications. Darien: American Academy of Sleep Medicine; 2017.

7. Epstein LJ, Kristo D, Strollo PJ Jr, Friedman N, Malhotra A, Patil SP, et al. Clinical guidelines for the evaluation, management and long-term care of obstructive sleep apnea in adults. J Clin Sleep Med. 2009;5(3):263-76.

8. Douglass AB, Bornstein R, Nino-Murcia G, Keenan S, Miles L, Zarcone VP Jr, et al. The sleep disorders questionnaire. I. Creation and multivariate structure of SDQ. Sleep. 1994;17:160-7.

9. Weatherwax KJ, Lin X, Marzec ML, Malow BA. Obstructive sleep apnea in epilepsy patients: the sleep apnea scale of the sleep disorders questionnaire (SA-SDQ) is a useful screening instrument for obstructive sleep apnea in a disease specific population. Sleep Med. 2003;4(6):517-21.

10. Merikangas KR, Zhang J, Emsellem H, Swanson SA, Vgontzas A, Belouad F, et al. The structured diagnostic interview for sleep patterns and disorders: rationale and initial evaluation. Sleep Med. 2014;15(5):530-5.

11. Peppard PE, Young T, Dempsey J, Dempsey J, Skatrud J. Longitudinal study of moderate weight change and sleep-disordered breathing. JAMA. 2000;284:3015-21.

12. Decary A, Rouleau I, Montplaisir J. Cognitive deficits associated with sleep apnea syndrome: a proposed neuropsychological test battery. Sleep. 2000;23:369-81

13. Abad-Alegria F, Lopez-Mallen ME, de Francisco-Maqueda P. Insomnia and somnolence in epilepsy. Rev Neurol. 1997;25:1171-2 [In Spanish].

14. Malow BA, Vaughn BV. Treatment of sleep disorders in epilepsy. Epilepsy and Behav. 2002:3:35-7.

15. So EL, Sam MC, Lagerlund TL. Postictal central apnea as a cause of SUDEP: evidence from near-SUDEP incident. Epilepsia. 2000:41:1494-7.

16. Herman ST, Walczak TS, Bazil CW. Distribution of partial seizures during the sleep-wake cycle: differences by seizure onset site. Neurology. 2001;56:1453-9.

17. Beran RG, Holland GJ, Yan KY. The use of CPAP in patients with refractory epilepsy. Seizure. 1997:6:323-5.

18. Koh S, Ward SL, Lin M, Chen LS. Sleep apnea treatment improves seizure control in children with neurodevelopmental disorders. Pediatr Neurol. 2000;22:36-9.

19. Vendrame M, Auerbach S, Loddenkemper T, Kothare S, Montouris G. Effect of continuous positive airway pressure treatment on seizure control in patients with obstructive sleep apnea and epilepsy. Epilepsia. 2011:52:168-71.

20. Girardin JL, Zizi F, Clark LT, Brown CD, McFarlane SI. Obstructive sleep apnea and cardiovascular disease: role of the metabolic syndrome and its components. J Clin Sleep Med. 2008;4:261-72.

21. Vaughn BV, Cruz OF, Beach R, Messenheimer JA. Improvement of epileptic seizure control with treatment of obstructive sleep apnea. Seizure. 1996;5:73-8.

22. Oliveira AJ, Zamagni M, Dolso P, Bassetti MA, Gigli GL. Respiratory disorders during sleep in patients with epilepsy: effect of ventilatory therapy on EEG interictal epileptiform discharges. Clin Neurophysiol. 2000;111(S2):141-5.

23. Young TR, Palta M, Dempsey J, Skatrud J, Weber S, Badr S. The occurrence of sleep-disordered breathing among middle-aged adults. N Engl J Med. 1993;328:1230-5.

24. Foldvary-Schaefer N, Andrews ND, Pornsriniyom D, Moul DE, Sun Z, Bena J. Sleep apnea and epilepsy: who's at risk? Epilepsy Behav. 2012;25:363-7.

25. Li P, Ghadersohi S, Jafari B, Teter B, Sazgar M. Characteristics of refractory vs. medically controlled epilepsy patients with obstructive sleep apnea and their response to CPAP treatment. Seizure. 2012;21:717-21.
26. Zanzmera P, Garima Shukla G, Gupta A, Singh H, Goyal V, Srivastava A, et al. Markedly disturbed sleep in medically refractory compared to controlled epilepsy - a clinical and polysomnography study. Seizure. 2012;21:487-90.

27. Ryvlin P, Cucherat M, Rheims S. Risk of sudden unexpected death in epilepsy in patients given adjunctive antiepileptic treatment for refractory seizures: a meta-analysis of placebo-controlled randomised trials. Lancet Neurol. 2011;10:961-8.

28. Nobili L, Proserpio P, Rubboli G, Montano N, Didato G, Tassinari CA. Sudden unexpected death in epilepsy (SUDEP) and sleep. Sleep Med Rev. 2011;15:237-46.

29. Dominici M, Pompeu Filho F, Gomes MM. Probable causal link between epilepsy and sleep apnea: case report. Arq Neuropsiquiatr. 2007;65(1):164-6.

30. Manni R, Terzaghi M, Arbasino C, Sartori I, Galimberti CA, Tartara A. Obstructive sleep apnea in a clinical series of adult epilepsy patients. Frequency and features of the comorbidity. Epilepsia. 2003;44(6):836-40

31. de Weerd A, de Haas S, Otte A, Trenité DK, van Erp G, Cohen A, et al. Subjective sleep disturbance in patients with partial epilepsy: a questionnaire-based study on prevalence and impact on quality of life. Epilepsia. 2004;45(11):1397-404.

\section{Submit your manuscript to a SpringerOpen ${ }^{\circ}$ journal and benefit from:}

- Convenient online submission

- Rigorous peer review

- Open access: articles freely available online

- High visibility within the field

- Retaining the copyright to your article

Submit your next manuscript at $>$ springeropen.com 